\title{
MicroRNA-30a suppresses papillary thyroid cancer cell proliferation, migration and invasion by directly targeting E2F7
}

\author{
HAIYAN GUO $^{1}$ and LINYUN ZHANG ${ }^{2}$ \\ ${ }^{1}$ Department of Clinical Medicine, Fenyang College, Shanxi Medical University; \\ ${ }^{2}$ Shanxi Fenyang Prison Hospital, Fenyang, Shanxi 032200, P.R. China
}

Received June 3, 2018; Accepted February 5, 2019

DOI: $10.3892 /$ etm.2019.7532

\begin{abstract}
RNA (miRNA/miR)-30a, a tumor-associated miRNA, has been implicated in the tumorigenesis and progression of different types of human cancer. Thyroid cancer is a common endocrine malignancy, of which papillary thyroid cancer (PTC) accounts for $\sim 80-90 \%$ of all TC. However, the effect of miR-30a in PTC is yet to be fully elucidated. The TPC-1 human PTC cell line, as well as the normal human thyroid cell line (HT-ori3), were utilized in the current study. The PTC cell line was transfected with a miR-30a mimic. Subsequently, reverse transcription-quantitative polymerase chain reaction was performed to detect the expression of miR-30a and E2F transcription factor 7 (E2F7). Cell proliferation was assessed via a MTT assay and transwell migration and invasion assays were performed to detect the migration and invasion of PTC cells. A dual-luciferase reporter assay was also utilized to clarify the association between miR-30a and E2F7. The results of the current study revealed that miR-30a was significantly downregulated in TPC-1 cells compared with HT-ori3 cells and that the expression of E2F7 was significantly upregulated in PTC cells. The upregulation of miR-30a also inhibited the proliferation, migration and invasion of PTC cells. Furthermore, the luciferase assay revealed that miR-30a binds to the 3'-UTR of E2F7. Additionally, the overexpression of miR-30a decreased E2F7 levels in TPC-1 cells. These results indicate that miR-30a functions as a tumor suppressor in PTC by direct targeting E2F7 and that miR-30a may be a novel therapeutic target for patients with PTC.
\end{abstract}

\section{Introduction}

The incidence of thyroid cancer (TC) is the highest among endocrine malignancies (1-4), with $\sim 62,450$ new diagnoses

Correspondence to: Professor Haiyan Guo, Department of Clinical Medicine, Fenyang College Shanxi Medical University, 16 Yingxiong Road, Fenyang, Shanxi 032200, P.R. China

E-mail: guohysx@163.com

Key words: papillary thyroid cancer, microRNA-30a, cell viability, cell migration assays, cell invasion, E2F transcription factor 7 and 1,950 TC mortalities in 2015 alone (5). Furthermore, the incidence of TC has increased rapidly in recent years and as such has attracted more scientific attention; the age-adjusted incidence of TC is estimated to be 9.1 per 100,000 females and 2.9 per 100,000 males in developed countries (6-9). TC can be divided into four histologic groups, including papillary TC (PTC), poorly differentiated carcinoma, follicular TC and anaplastic TC (10). Among these, PTC accounts for $~ 80-90 \%$ of all patients with TC (10). PTC has a poor prognosis, so studies assessing the molecular mechanism of PTC development are urgently required (11-14).

MicroRNAs (miRNAs) are small non-coding RNA molecules comprised of 20-22 nucleotides, which inhibit mRNA expression at the post-transcriptional level $(15,16)$. Several studies have demonstrated that various miRNAs function as promoters or suppressors in many types of tumor, meaning that the identification of miRNAs may serve as a useful diagnostic and therapeutic approaches to cancer $(10,17,18)$. Furthermore, previous studies have reported the use of miRNAs as biomarkers and their impact on the development of therapeutic strategies in various malignancies, including lung cancer (18), TC (19) and prostate cancer (20). Therefore, the identification of novel biomarkers and molecular targets may provide more effective treatment options for patients with PTC.

The results of the current study determined the expression of miR-30a in two TC cell lines and identified the effect of miR-30a on the viability, migration and invasion of PTC cells. These data indicated that miR-30a was downregulated in PTC cells, while its ectopic overexpression significantly inhibited the viability, migration and invasion of PTC cells. Therefore, miR-30a may have the potential to function as a diagnostic biomarker or a curative target in the future diagnosis and treatment of patients with PTC.

\section{Materials and methods}

Study sample. A total of 15 pairs of PTC tissues and matched adjacent non-tumor tissues were obtained from Fenyang Prison Hospital (Fenyang, China). All tissue samples were obtained following the receipt of written informed consent. The current study was approved by the Ethics Review Board of Fenyang College Shanxi Medical University (Shanxi, China). Seven tissue samples were from males and eight were from females. The average age of the study population was 58.4 years (range, 
47-78 years). The data range of sample collection was between October 2017 and May 2018. The patients who were diagnosed with PTC were included in the study. The diagnoses were made by pathologists. Adjacent non-tumor tissues were isolated $\geq 2 \mathrm{~cm}$ away from the tumor border and were shown to be free of tumor cells via microscopy. The tissues were fixed with $10 \%$ formalin for $24 \mathrm{~h}$ at room temperature, processed in paraffin and sectioned using a microtome. The thickness of sections was $20 \mu \mathrm{m}$. Hematoxylin and eosin staining was used to confirm the diagnosis. Briefly, the tissue was stained in hematoxylin for $4 \mathrm{~min}$ at room temperature, washed under running tap water for $5 \mathrm{~min}$, differentiated in $1 \%$ acid alcohol for $5 \mathrm{~min}$ at room temperature, and under running tap water for $5 \mathrm{~min}$. The tissues were stained in $1 \%$ eosin $\mathrm{Y}$ for $10 \mathrm{~min}$ at room temperature, washed under running tap water for 5 min, and then dehydrated $95 \%$ ethanol and absolute ethanol. Subsequently, the tissues were cleared in xylene. The samples were observed under a light microscope at a magnification of x100. Following tissue collection, samples were frozen in liquid nitrogen immediately, transported to the laboratory and stored at $-80^{\circ} \mathrm{C}$ for RNA isolation. Following resection, tissues were washed with PBS, immediately frozen in liquid nitrogen and stored at $-80^{\circ} \mathrm{C}$. The expression of miR-30a in PTC tissue was then compared with adjacent non-tumor tissues.

Cell culture. The TPC-1 cell line and the normal PTC cell line (HT-ori3) were purchased from the American Type Culture Collection (Manassas, VA, USA). Cells were maintained in RPMI-1640 medium (Invitrogen; Thermo Fisher Scientific, Inc., Waltham, MA, USA) supplemented with $10 \%$ fetal bovine serum (Invitrogen; Thermo Fisher Scientific, Inc.), 100 IU/ml of penicillin and $100 \mu \mathrm{g} / \mathrm{ml}$ of streptomycin. All cells were cultured in a humidified incubator containing $5 \% \mathrm{CO}_{2}$ at $37^{\circ} \mathrm{C}$.

miRNA transfection. miR-30a mimics (20 nmol/l) and negative control (NC) miRNA (20 nmol/1) were acquired from Shanghai GenePharma Co., Ltd. (Shanghai, China). The miR-30a mimics sequence was 5'-UGUAAACAUCCU CGACUGGAAG-3'. The NC miRNA sequence was 5'-ACA UUUGUAGGAGCUGACCGGC-3'. Lipofectamine $2000^{\circledR}$ (Invitrogen; Thermo Fisher Scientific, Inc.) was subsequently utilized to perform transient transfection following incubation at $37^{\circ} \mathrm{C}$ for $6 \mathrm{~h}$. Transfected cells were collected and purified after $48 \mathrm{~h}$ incubation.

Reverse transcription-quantitative polymerase chain reaction (RT-qPCR). RNA was extracted from cultured cells and tissues using the TRIzol ${ }^{\circledR}$ reagent (Invitrogen; Thermo Fisher Scientific, Inc.). Subsequently, RNA was reverse transcribed using the RevertAid First Strand cDNA Synthesis kit (Thermo Fisher Scientific, Inc.). qPCR was performed to determine the expression of miR-30a and E2F transcription factor 7 (E2F7) using SYBRGreen (Qiagen, Inc., Valencia, CA, USA). RT-qPCR amplification was performed for 40 cycles using the following thermal profile: Denaturation for $15 \mathrm{sec}$ at $95^{\circ} \mathrm{C}$, annealing and extension for $1 \mathrm{~min}$ at $60^{\circ} \mathrm{C}$. The following primers were utilized: miR-30a forward, 5'-CGCGATGTG TAAACATCCTCGAC-3' and reverse, 5'-ATCCAGTGCAGG GTCCGAGG-3'; E2F7 forward, 5'-ACCCTCAGATTCCAC AGACC-3' and reverse, 5'-AGTTTGCTGTTGCCTTTCCT-3';
U6 forward, 5'-CTCGCTTCGGCAGCACA-3' and reverse, 5'-AACGCTTCACGAATTTGCGT-3'. U6 served as an internal control. Furthermore, the $2^{-\Delta \Delta \mathrm{Cq}}$ method was utilized for RNA quantification and associated analysis (21).

MTT assay. Cell viability was assessed via an MTT assay. Cultured TPC-1 cells were first transfected with the miRNA mimics, then seeded into 96-well plates $(\sim 4,000$ cells/well). Subsequently, MTT solution (Sigma-Aldrich; Merck KGaA, Darmstadt, Germany) was added to each well and incubated at $37^{\circ} \mathrm{C}$ for $4 \mathrm{~h}$. A solubilization solution, dimethyl sulfoxide, was added to dissolve the insoluble purple formazan. A microplate reader was used for detecting the viability of cells at an absorbance at $490 \mathrm{~nm}$.

Invasion and migration assays. Transwell inserts that were precoated with Matrigel (BD Biosciences, San Jose, CA, USA) were utilized to identify the effect of miR-30a on the invasive capacity of PTC cells. PTC cells $\left(1 \times 10^{5}\right)$ were suspended in Dulbecco's Modified Eagle's medium (DMEM; Thermo Fisher Scientific, Inc.) without serum. Subsequently, these cells and medium were seeded into the upper chamber of the system and DMEM containing 20\% FBS was added to the lower chamber. Cells were incubated at $37^{\circ} \mathrm{C}$ for $24 \mathrm{~h}$ and fixed using $4 \%$ polyoxymethylene at $4^{\circ} \mathrm{C}$ for $15 \mathrm{~min}$. Following $15 \mathrm{~min}$ of incubation at $4^{\circ} \mathrm{C}$, samples were stained using $0.1 \%$ crystal violet dye for $10 \mathrm{~min}$ at $37^{\circ} \mathrm{C}$. The experimental procedure for the migration assay was the same as aforementioned, except the transwell inserts were not coated with Matrigel prior to experimentation. A light microscope was utilized to visualize the results at magnification, x200. Each assay was performed in triplicate and repeated three times.

Western blotting. Protein from TPC-1 cells was extracted using modified radioimmunoprecipitation assay buffer containing $0.5 \%$ sodium dodecyl sulfate (SDS) in the presence of a proteinase inhibitor cocktail (all Roche Applied Science, Madison, WI, USA) at $96 \mathrm{~h}$ following transfection. A bicinchoninic acid assay was used for the detection of protein concentration. Protein ( $2 \mu \mathrm{g}$ per lane) was then separated using $10 \%$ SDS-PAGE and transferred onto a polyvinylidene difluoride membrane. Membranes were blocked with 5\% non-fat at room temperature for $1 \mathrm{~h}$ and incubated with the following primary antibodies at $4^{\circ} \mathrm{C}$ overnight: Anti-E2F7 (cat. no. sc-32574; 1:5,000; Santa Cruz Biotechnology, Inc., Dallas, TX, USA) and anti-GAPDH (cat. no. 2118; 1:5,000; Cell Signaling Technology, Inc.). Samples were then incubated with horseradish peroxidase-conjugated goat anti-rabbit immunoglobulin G secondary antibodies (cat. no. 65-6120; 1:5,000; Invitrogen; Thermo Fisher Scientific, Inc.) at $4^{\circ} \mathrm{C}$ overnight. Immunoreactive bands were visualized on film by enhanced chemiluminescent substrate (Pierce; Thermo Fisher Scientific, Inc.). GAPDH was utilized as an internal control and data were analyzed using Image J software version 1.8 (National Institutes of Health, Bethesda, MD, USA).

Luciferase reporter assay. TargetScan (www.targetscan. org/) was used to predict the target gene of miR-30a. To determine the association between miRNA and target genes, PCR was used to amplify the 3'-untranslated region (UTR) of 
human E2F7, which was then cloned into a pmirGLO vector (Promega Corporation, Madison, WI, USA). The PCR method used is detailed in the previous subsection. Subsequently, Lipofectamine $2000^{\circledR}$ was utilized to transfect cells in the 24-well plates. The obtained wild type or mutant pmirGLO vector, pRL-SV40 Renilla luciferase construct (5 ng; Promega Corporation) and miR-30a mimic or the respective negative control were co-transfected to each well. After $48 \mathrm{~h}$ transfection, cells were extracted and the luciferase activity was determined using the Dual luciferase reporter assay system (DLR ${ }^{\circledR}$ Assay) following $48 \mathrm{~h}$. Firefly luciferase activity in the vectors was normalized to Renilla luciferase activity.

Statistical analysis. Data were analyzed using GraphPad Prism 6.0 software (GraphPad Software, Inc., La Jolla, CA, USA) and presented as the mean \pm standard deviation. One-way analysis of variance followed by a Tukey's post-hoc test was used for comparisons between multiple groups. $\mathrm{P}<0.05$ was considered to indicate a statistically significant difference.

\section{Results}

miR-30a is downregulated in human PTC tissue. To obtain a greater understanding of the clinical interrelation of the expression of miR-30a in PTC tissue, 15 pairs of PTC tissue samples and non-tumor tissues were assessed via RT-qPCR. The results revealed that the expression of miR-30a was significantly downregulated in PTC tissue compared with non-tumor tissue (Fig. 1).

miR-30a is downregulated and E2F7 is upregulated in human PTC cells. The current study aimed to determine the expression of miR-30a in a PTC cell line (TPC-1) and a normal thyroid cell line (HT-ori3). Compared with HT-ori3 cells, the expression of miR-30a and the levels of E2F7 in TCP-1 cells were significantly decreased and increased, respectively (Fig. 2A-B). Western blotting was subsequently performed to detect the protein expression of E2F7 in these cell lines. The results revealed that E2F7 levels in TPC-1 cells were markedly increased compared with HT-ori3 cells (Fig. 2C-D).

miR-30a decreases the proliferation of TPC-1 cells. To determine whether miR-30a regulates the proliferation of PTC cells, miR-30a mimics were utilized to increase the expression of miR-30a. Following transfection for $6 \mathrm{~h}$, a significant increase in miR-30a expression was observed when compared with the NC mimic group (Fig. 3A). An MTT assay was subsequently performed to determine the proliferation of TPC-1 cells following miR-30a mimic or NC mimic transfection. The results revealed that transfection with miR-30a mimics significantly decreased cell proliferation compared with the NC mimics group. Furthermore, the proliferation of cells in the miR-30a mimic group achieved the minimal viability rate and become stable after $48 \mathrm{~h}$ (Fig. 3B). These results confirmed that the upregulation of miR-30a inhibits the proliferation of PTC cells.

miR-30a inhibits the migration and invaison of TPC-1 cells. To assess the roles of miR-30a in PTC cell migration and invasion, transwell migration and invasion assays were performed

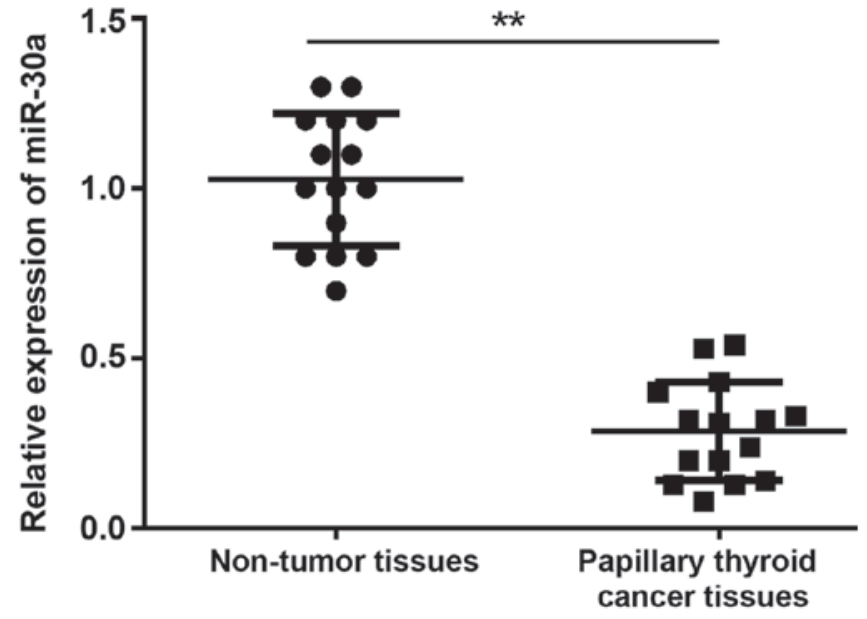

Figure 1. Expression of miR-30a in PTC tissues. Reverse transcription-quantitative polymerase chain reaction results revealed that miR-30a mRNA was significantly downregulated in PTC tissues compared with matched adjacent non-tumor tissues. ${ }^{* *} \mathrm{P}<0.01$ vs. non-tumor tissues. $\mathrm{miR}$, microRNA; PTC, papillary thyroid cancer.

in TPC-1 cells transfected with miR-30a or NC mimics. The results indicated that the overexpression of miR-30a, induced via the transfection of a miR-30a mimic, significantly suppressed the migration (Fig. 4A) and invasion (Fig. 4B) of TPC-1 cells compared with the NC mimics group.

miR-30a targets the E2F7 3'-UTR directly. To identify the molecular mechanism of miR-30a in the regulation of cell survival, putative miR-30a targets were predicted via bioinformatics analysis (Fig. 5A). The results revealed that E2F7 is a direct target of miR-30a. A luciferase reporter assay was then performed to confirm whether miR-30a targets E2F7 directly (Fig. 5B). The results demonstrated that, compared with the NC mimics group, co-transfection with miR-30a mimics significantly decreased the luciferase activity of the wild-type E2F7-3'-UTR luciferase vector in TPC-1 cells. However, no significant effect on the luciferase activity of mutant E2F7-3'-UTR following transfection of miR-30a was observed. Furthermore, the protein levels of E2F7 were markedly decreased following miR-30a transfection (Fig. 5C). These data indicate that E2F7 may be a direct target of miR-30a in PTC cells.

\section{Discussion}

TC is a common endocrine malignancy that is primarily derived from follicular thyroid or parafollicular C cells (22). The overall 10-year survival rate of differentiated TC was $>80 \%$, with $\sim 5-20 \%$ of TC patients developing local or regional recurrence and 10-15\% developing distant metastases in a 2014 study (23). Furthermore, PTC accounts for $\sim 80-90 \%$ of all TC patients. In recent years, previous studies have aimed to assess certain miRNAs as possible regulators of tumorigenesis and PTC development (24-26). The current study aimed to assess the role of miR-30a in PTC via the regulation of E2F7. The results demonstrated that the overexpression of miR-30a suppressed the proliferation, migration and invasion of PTC cells by directly targeting E2F7. 

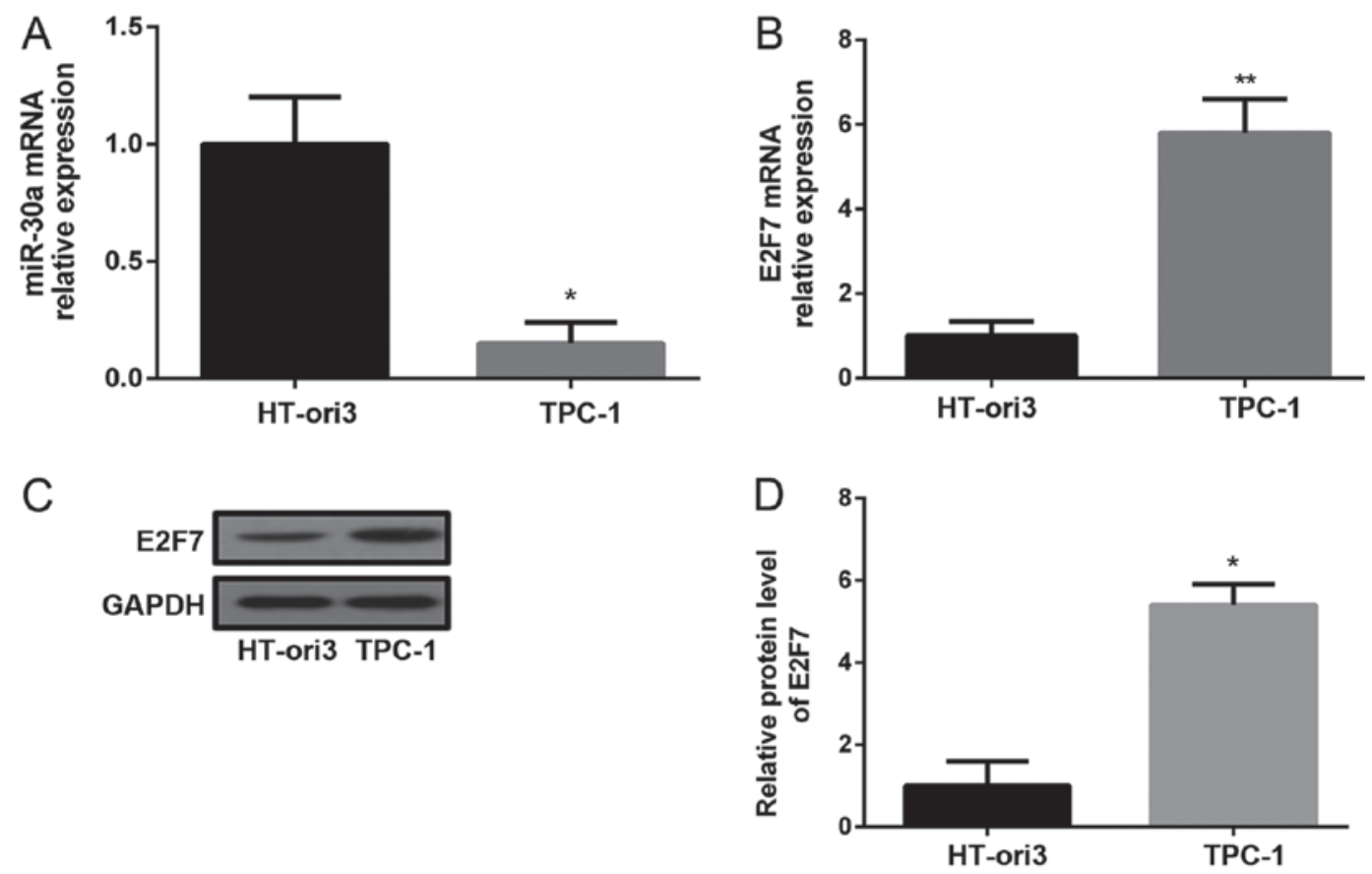

Figure 2. miR-30a and E2F7 are respectively downregulated and upregulated in TPC-1 cells. (A) miR-30a and (B) E2F7 expression was determined via reverse-transcription quantitative polymerase chain reaction analysis with U6 as a loading control. (C) Western blotting and subsequent (D) analysis revealed that E2F7 levels in the TPC-1 cells are markedly increased compared with HT-ori3 cells. Values are expressed as the mean \pm standard deviation. "P<0.05 and ${ }^{* *} \mathrm{P}<0.01$ vs. HT-ori3. miR, microRNA; E2F7, E2F transcription factor 7.
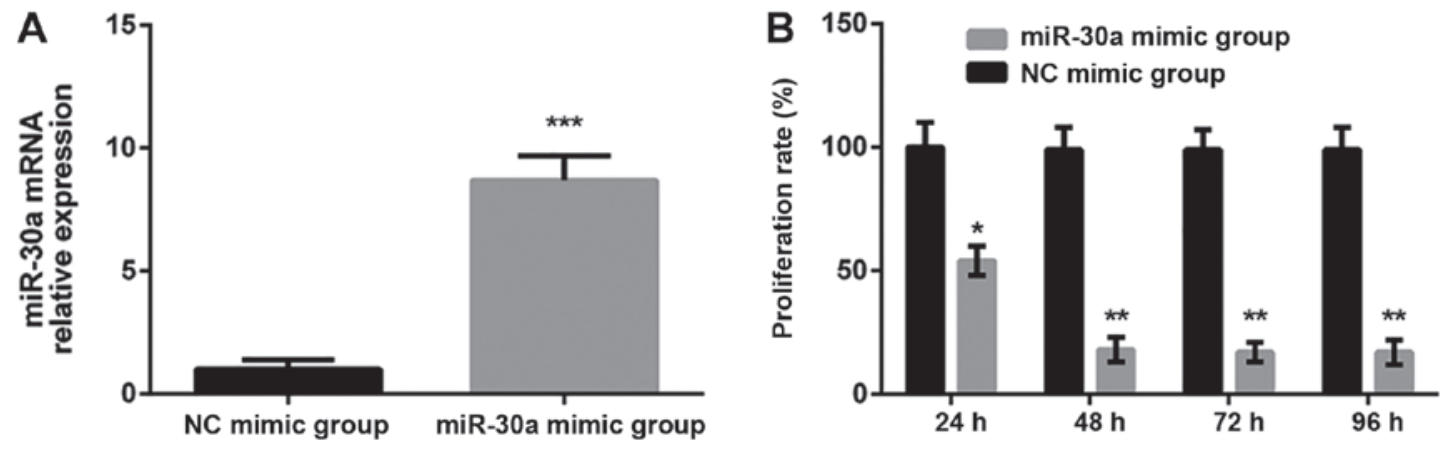

Figure 3. Overexpression of miR-30a inhibits the proliferation of TPC-1 cells. (A) Following transfection, the expression of miR-30a was determined via reverse-transcription quantitative polymerase chain reaction analysis. (B) Cell proliferation was then assessed in different groups at $24,48,72$ and $96 \mathrm{~h}$ via an MTT assay. ${ }^{*} \mathrm{P}<0.05,{ }^{* *} \mathrm{P}<0.01$ and ${ }^{* * *} \mathrm{P}<0.01$ vs. NC mimic group. miR, microRNA.

Previous studies have demonstrated that miRNAs serve as tumor suppressors in various types of cancer (27-30). A previous study revealed that miR-141 suppressed TC cell growth and metastasis by suppressing insulin receptor substrate 2, indicating that miR-141 may serve as a potential therapeutic target for the treatment of patients with TC (31). Furthermore, miR-497 is also considered to be a TC tumor suppressor that acts by repressing brain derived neurotrophic factor (32). A previous study also indicated that miR-7 may function as a tumor suppressor by directly targeting serine/threonine protein kinase 1, potentially serving as a novel therapeutic target for TC (30). Therefore, miRNAs have been demonstrated to be associated with tumor development and progression, highlighting their potential use as biomarkers for the diagnosis and prognosis of PTC. However, the prognostic relevance and functions of miR-30a in PTC remain largely unclear. The current study assessed the expression of miR-30a and their role in PTC cells. The results indicated that miR-30a was downregulated in PTC cell lines compared with normal cell lines. Furthermore, the ectopic expression of miR-30a inhibited PTC cell proliferation, migration and invasion.

It is well known that E2F7 serves predominantly as a transcriptional repressor, binding to miRNA promoters and protein-coding genes bearing E2F consensus motifs, thereby inhibiting their expression (33). The E2F family of transcription factors are important regulators of cellular proliferation (34). A previous study has revealed that the $\mathrm{E} 2 \mathrm{~F} 7$ protein serves an essential role in the regulation of cell cycle progression and may be a key component of a negative feedback loop required to turn off the transcription of E2F-driven $\mathrm{G} 1 / \mathrm{S}$ target genes, thus allowing progression through the cell cycle (35). The p53-dependent transcriptional upregulation of E2F7 results in the repression of relevant gene expression and the E2F7-dependent mechanism contributes to p53-dependent cell 

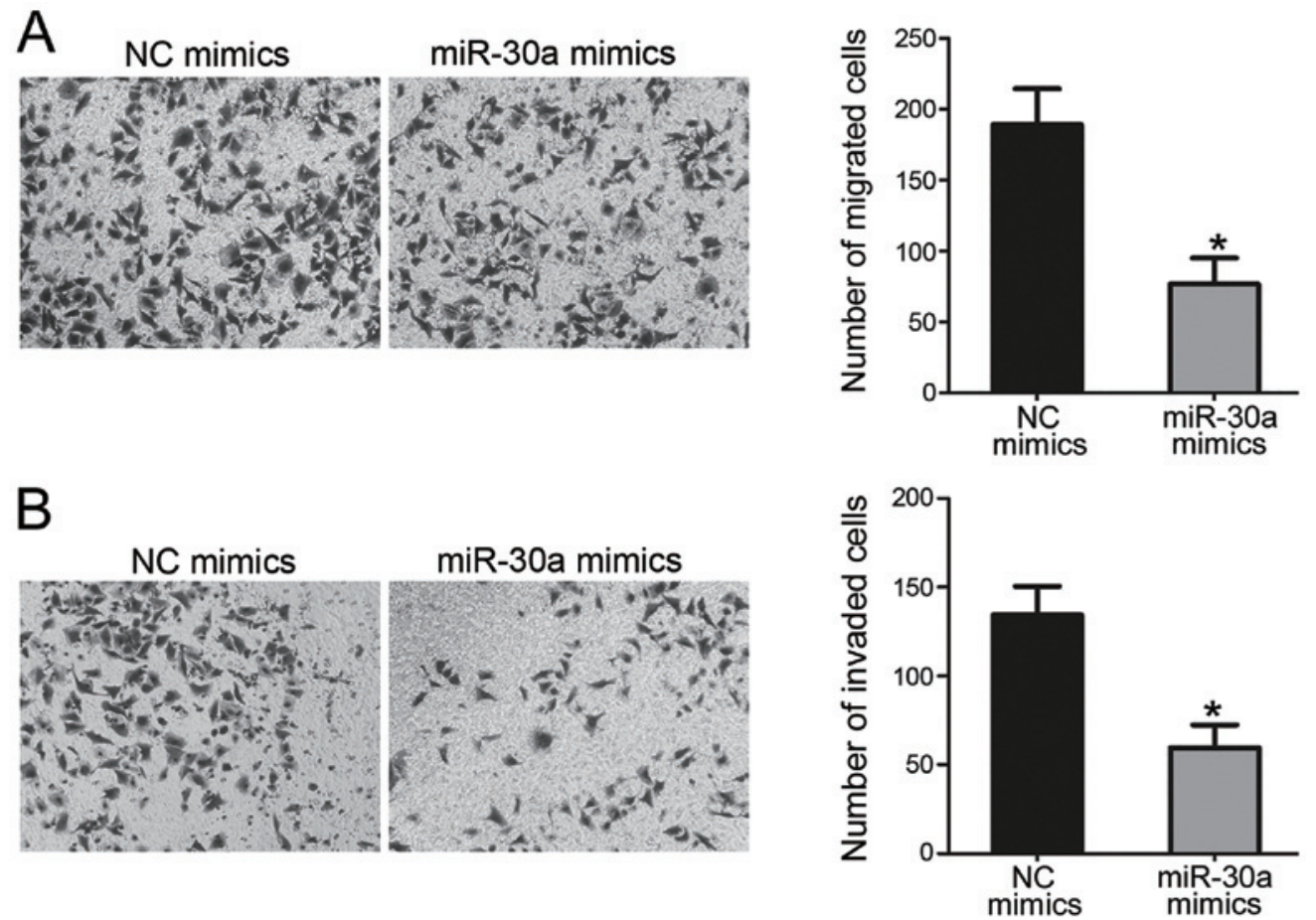

Figure 4. Overexpression of miR-30a suppresses the migration and invasion of TPC-1 cells. TPC-1 cells were transfected with miR-30a mimics or NC mimics. $48 \mathrm{~h}$ following, transwell migration and invasion assays were performed to determine cell (A) migration and (B) Invasion. "P<0.05 vs. the miR-30a mimics group. miR, microRNA; NC, negative control.

\section{A miR-30a: 3' GAAGGUCAGCUCCUACAAAUGU 5' \\ E2F7-wt: 5' GAUUUAGUGCAAAAAGUUUACAA 3' E2F7-mut: 5' GAUUUAGUGCAAAAAACCCCAAA 3'}

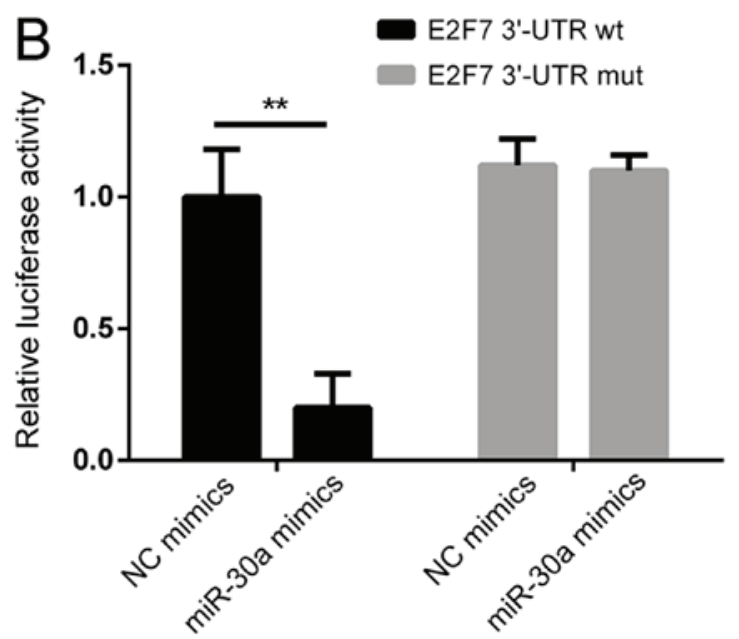

C

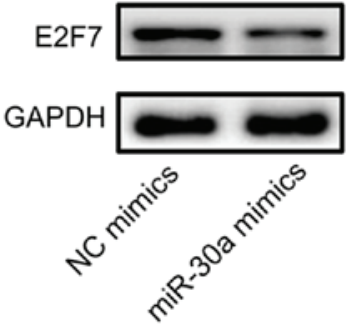

Figure 5. miR-30a directly targets the 3'-UTR of E2F7 mRNA. (A) Schematic representation of the mature miR-30a sequence and the putative miR-30a target site in the 3'-UTR of E2F7 mRNA (red font). (B) Overexpression of miR-30a markedly decreased the relative luciferase activity of the E2F7 3'-UTR wt group, while the E2F7 3'-UTR mut group demonstrated no marked effect. (C) The protein expression of E2F7 following incubation with miR-30a mimics was measured via western blotting. ${ }^{* *} \mathrm{P}<0.01$. miR, microRNA; UTR, untranslated region; E2F7, E2F transcription factor 7; NC, negative control; wt, wild-type; mut, mutant.

cycle arrest in response to DNA damage (36). Furthermore, E2F7 may serve as an independent prognostic factor of glioma and may therefore constitute a potential therapeutic target for this disease (37). A recent study demonstrated that the inhibition of E2F7 inhibits gallbladder cancer cell proliferation, migration and metastasis (38). In the current study, miR-30a was confirmed to target E2F7 directly and the increased expression of miR-30a significantly suppressed E2F7 expression in human PTC cells. Furthermore, the results of transwell migration and invasion assays indicated 
that the overexpression of miR-30a, induced via transfection with miR-30a mimics, significantly suppressed the migration and invasion of PTC cells. In future experiments, studies will aim to perform other functional assays to determine the effect of miR-30a on the proliferation and metastasis of PTC cells in vitro and in vivo, including cell cycle analysis by flow cytometry and wound healing assay. Collectively, the current study revealed that miR-30a inhibited cell proliferation, migration and invasion, partially by targeting E2F7. Therefore, the current study provided evidence for the critical regulatory axis of miR-30a/E2F7 in the developmental process of PTC.

Overall, the current study demonstrated that the proliferation, migration and invasion of PTC cells are inhibited by miR-30a overexpression by targeting E2F7. All results obtained in the current study indicate that miR-30a may serve as a tumor suppressor gene in the tumorigenesis and progression of PTC. Therefore, miR-30a and E2F7 may serve as potential therapeutic targets for the treatment of patients with PTC.

\section{Acknowledgements}

Not applicable.

\section{Funding}

No funding received.

\section{Availability of data and materials}

The datasets used and/or analyzed during the present study are available from the corresponding author on reasonable request.

\section{Authors' contributions}

GY conceived the current study, wrote the paper and created the figures. GY and ZY performed the experiments, searched the literature, analyzed the data, created the tables and reviewed the manuscript.

\section{Ethics approval and consent to participate}

All tissue samples were obtained following the receipt of written informed consent. The current study was approved by the Ethics Review Board of Fenyang College Shanxi Medical University (Shanxi, China).

\section{Patient consent for publication}

Not applicable.

\section{Competing interests}

The authors declare that they have no competing interests.

\section{References}

1. Wang J, Yang H, Si Y, Hu D, Yu Y, Zhang Y, Gao M and Zhang H: Iodine promotes tumorigenesis of thyroid cancer by suppressing Mir-422a and up-regulating MAPK1. Cell Physiol Biochem 43: $1325-1336,2017$.
2. Kaptan E, Sancar-Bas S, Sancakli A, Bektas S and Bolkent S: The effect of plant lectins on the survival and malignant behaviors of thyroid cancer cells. J Cell Biochem 119: 6274-6287, 2018.

3. Sokić SI, Adanja BJ, Vlajinac HD, Janković RR, Marinković JP and Zivaljević VR: Risk factors for thyroid cancer. Neoplasma 41: 371-374, 1994.

4. Takacsova E, Kralik R, Waczulikova I, Zavodna K and Kausitz J: A different prognostic value of BRAFV600E mutation positivity in various age groups of patients with papillary thyroid cancer. Neoplasma 64: 156-164, 2017.

5. Di W, Li Q, Shen W, Guo H and Zhao S: The long non-coding RNA HOTAIR promotes thyroid cancer cell growth, invasion and migration through the miR-1-CCND2 axis. Am J Cancer Res 7: 1298-1309, 2017.

6. Xing M, Haugen BR and Schlumberger M: Progress in molecular-based management of differentiated thyroid cancer. Lancet 381: 1058-1069, 2013.

7. Ding ZY, Huang YJ, Tang JD, Li G, Jiang PQ and Wu HT: Silencing of hypoxia-inducible factor-1 $\alpha$ promotes thyroid cancer cell apoptosis and inhibits invasion by downregulating WWP2, WWP9, VEGF and VEGFR2. Exp Ther Med 12:3735-3741, 2016.

8. Lim ST, Jeon YW and Suh YJ: The prognostic values of preoperative tumor volume and tumor diameter in T1N0 papillary thyroid cancer. Cancer Res Treat 49: 890-897, 2017.

9. Rachinsky I, Rajaraman M, Leslie WD, Zahedi A, Jefford C, McGibbon A, Young JE, Pathak KA, Badreddine M, De Brabandere S, et al: Regional variation across Canadian centers in radioiodine administration for thyroid remnant ablation in well-differentiated thyroid cancer diagnosed in 2000-2010. J Thyroid Res 2016: 2867916, 2016.

10. Guan H, Liang W, Xie Z, Li H, Liu J, Liu L, Xiu L and Li Y: Down-regulation of miR-144 promotes thyroid cancer cell invasion by targeting ZEB1 and ZEB2. Endocrine 48: 566-574, 2015.

11. Vasko VV and Saji M: Molecular mechanisms involved in differentiated thyroid cancer invasion and metastasis. Curr Opin Oncol 19: 11-17, 2007.

12. Liao T, Wang YJ, Hu JQ, Wang Y, Han LT, Ma B, Shi RL, Qu N, Wei WJ, Guan Q, et al: Histone methyltransferase KMT5A gene modulates oncogenesis and lipid metabolism of papillary thyroid cancer in vitro. Oncol Rep 39: 2185-2192, 2018.

13. Lu ZL, Chen YJ, Jing XY, Wang NN, Zhang T and Hu CJ: Detection and identification of serum peptides biomarker in papillary thyroid cancer. Med Sci Monit 24: 1581-1587, 2018.

14. Zhao W, Chen S, Hou X, Chen G and Zhao Y: CHK2 promotes anoikis and is associated with the progression of papillary thyroid cancer. Cell Physiol Biochem 45: 1590-1602, 2018.

15. Shi Z, Zhou H, Lu L, Li X, Fu Z, Liu J, Kang Y, Wei Z, Pan B, Liu L, et al: The roles of microRNAs in spinal cord injury. Int J Neurosci 127: 1104-1115, 2017.

16. Ouyang Q, Xu L, Cui H, Xu M and Yi L: MicroRNAs and cell cycle of malignant glioma. Int J Neurosci 126: 1-9, 2016.

17. Chen X, Ba Y, Ma L, Cai X, Yin Y, Wang K, Guo J, Zhang Y, Chen J, Guo X, et al: Characterization of microRNAs in serum: A novel class of biomarkers for diagnosis of cancer and other diseases. Cell Res 18: 997-1006, 2008.

18. Wang RJ, Zheng YH, Wang P and Zhang JZ: Serum miR-125a-5p, miR-145 and miR-146a as diagnostic biomarkers in non-small cell lung cancer. Int J Clin Exp Pathol 8: 765-771, 2015.

19. Fuziwara CS and Kimura ET: MicroRNA deregulation in anaplastic thyroid cancer biology. Int J Endocrinol 2014: 743450, 2014.

20. Costa-Pinheiro P,Ramalho-Carvalho J, VieiraFQ, Torres-Ferreira J, Oliveira J, Gonçalves CS, Costa BM, Henrique R and Jerónimo C: MicroRNA-375 plays a dual role in prostate carcinogenesis. Clin Epigenetics 7: 42, 2015.

21. Livak KJ and Schmittgen TD: Analysis of relative gene expression data using real-time quantitative PCR and the 2(-Delta Delta C(T)) method. Methods 25: 402-408, 2001.

22. Xing M: Molecular pathogenesis and mechanisms of thyroid cancer. Nat Rev Cancer 13: 184-199, 2013.

23. Perros P, Boelaert K, Colley S, Evans C, Evans RM, Gerrard Ba G, Gilbert J, Harrison B, Johnson SJ, Giles TE, et al: Guidelines for the management of thyroid cancer. Clin Endocrinol (Oxf) 81 (Suppl 1): S1-S122, 2014.

24. Bi CL, Zhang YQ, Li B, Guo M and Fu YL: MicroRNA-520a-3p suppresses epithelial-mesenchymal transition, invasion, and migration of papillary thyroid carcinoma cells via the JAK1-mediated JAK/STAT signaling pathway. J Cell Physiol 234: 4054-4067, 2019.

25. Liu H, Guo J, Chai H and Meng X: MicroRNA-744 suppresses cell proliferation and invasion of papillary thyroid cancer by directly targeting NOB1. Mol Med Rep 19: 1903-1910, 2019. 
26. Heidari Z, Mohammadpour-Gharehbagh A, Eskandari M, Harati-Sadegh M and Salimi S: Genetic polymorphisms of miRNA let7a-2 and pri-mir-34b/c are associated with an increased risk of papillary thyroid carcinoma and clinical/pathological features. J Cell Biochem: 14 Dec, 2018 (Epub ahead of print).

27. Damodaran M, Paul SFD and Venkatesan V: Genetic polymorphisms in miR-146a, miR-196a2 and miR-125a genes and its association in prostate cancer. Pathol Oncol Res: 29 Mar, 2018 (Epub ahead of print).

28. Mo JS, Park YR and Chae SC: MicroRNA 196B regulates HOXA5, HOXB6 and GLTP expression levels in colorectal cancer cells. Pathol Oncol Res: 12 Mar, 2018 (Epub ahead of print).

29. Seclaman E, Narita D, Anghel A, Cireap N, Ilina R, Sirbu IO and Marian C: MicroRNA expression in laser micro-dissected breast cancer tissue samples-a pilot study. Pathol Oncol Res 25: 233-239, 2019.

30. Yue K, Wang X, Wu Y, Zhou X, He Q and Duan Y: microRNA-7 regulates cell growth, migration and invasion via direct targeting of PAK1 in thyroid cancer. Mol Med Rep 14: 2127-2134, 2016.

31. Dong S, Meng X, Xue S, Yan Z, Ren P and Liu J: microRNA-141 inhibits thyroid cancer cell growth and metastasis by targeting insulin receptor substrate 2. Am J Transl Res 8: 1471-1481,2016.

32. Wang $P$, Meng X, Huang Y, Lv Z, Liu J, Wang G, Meng W, Xue S, Zhang Q, Zhang P and Chen G: MicroRNA-497 inhibits thyroid cancer tumor growth and invasion by suppressing BDNF. Oncotarget 8: 2825-2834, 2017.

33. Westendorp B, Mokry M, Groot Koerkamp MJ, Holstege FC, Cuppen E and de Bruin A: E2F7 represses a network of oscillating cell cycle genes to control S-phase progression. Nucleic Acids Res 40: 3511-3523, 2012.
34. Chen D, Pacal M, Wenzel P, Knoepfler PS, Leone G and Bremner R: Division and apoptosis of E2f-deficient retinal progenitors. Nature 462: 925-929, 2009.

35. Mitxelena J, Apraiz A, Vallejo-Rodríguez J, García-Santisteban I, Fullaondo A, Alvarez-Fernández $M$, Malumbres $M$ and Zubiaga AM: An E2F7-dependent transcriptional program modulates DNA damage repair and genomic stability. Nucleic Acids Res 46: 4546-4559, 2018.

36. Carvajal LA, Hamard PJ, Tonnessen C and Manfredi JJ: E2F7, a novel target, is up-regulated by $\mathrm{p} 53$ and mediates DNA damage-dependent transcriptional repression. Genes Dev 26: 1533-1545, 2012.

37. Yin W, Wang B, Ding M, Huo Y, Hu H, Cai R, Zhou T, Gao Z, Wang Z and Chen D: Elevated E2F7 expression predicts poor prognosis in human patients with gliomas. J Clin Neurosci 33: 187-193, 2016.

38. Ye YY, Mei JW, Xiang SS, Li HF, Ma Q, Song XL, Wang Z, Zhang YC, Liu YC, Jin YP, et al: MicroRNA-30a-5p inhibits gallbladder cancer cell proliferation, migration and metastasis by targeting E2F7. Cell Death Dis 9: 410, 2018.

This work is licensed under a Creative Commons Attribution-NonCommercial-NoDerivatives 4.0 International (CC BY-NC-ND 4.0) License. 